\title{
Noticias 2018
}

María Angélica Rozas Rozas Alvarez

Instituto de Investigaciones Museológicas y Artísticas / Universidad Ricardo Palma mrozas@urp.edu.pe

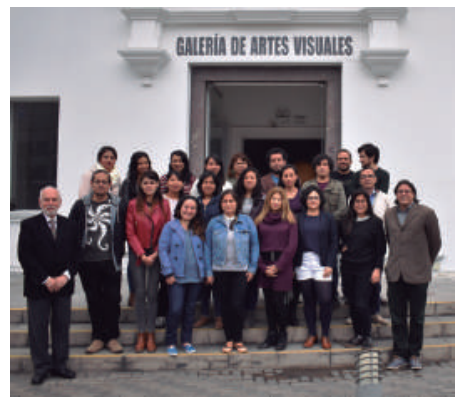

Le damos la bienvenida a la onceava promoción 2018-2019 de nuestra Maestría en Museología y Gestión Cultural. Les deseamos mucho éxito en esta nueva etapa de su vida académica, sobre todo en esta especialidad, tan necesaria en nuestro medio en el que necesitamos profesionales que velen por la integridad de nuestro patrimonio y su difusión. En la fotografía: el doctor Alfonso Castrillón, coordinador de la MMGC y el profesor Elio Martuccelli Casanova.

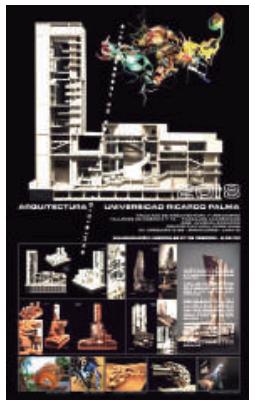

Exposición de los talleres "Talleres de Diseño V y XV 2018” organizados por los docentes y alumnos de la Facultad de Arquitectura y Urbanismo de la Universidad Ricardo Palma (FAU-URP). Como todos los años, se exhibió una selección de los mejores proyectos académicos de los alumnos dirigidos por el arquitecto Juvenal Baracco durante los semestres 2017-I y 2018-II. La muestra se presentó del 7 de febrero al 7 de marzo en la Galería de Artes Visuales.

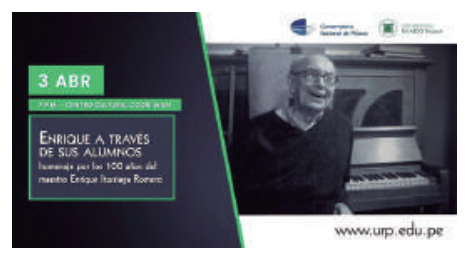

El 3 de abril se rindió el homenaje al maestro Enrique Iturriaga, uno de los más valiosos compositores de nuestro país, además de otorgarle la distinción como Profesor Honorario de la Universidad Ricardo Palma. La ceremonia estuvo a cargo de la Universidad Nacional de la Música (ex Conservatorio) y la Universidad Ricardo Palma, a través del Instituto de Investigaciones Museológicas y Artísticas. 
10 años de Xilografía, muestra de grabado de Luis Antonio Torres Villar, en la que con elementos de la tradición pictórica colonial y republicana, el artista hace una "denuncia sutil", a través de diversos temas, como la identidad cultural, la migración, las costumbres y tradiciones de "esta gran provincia que es Lima”. La exposición estuvo del 6 al 29 de abril.

El 28 de abril, la Galería de Artes Visuales, organizó el taller de grabado para niñas y niños de 10 a 15 años, "Mi primer Ex Libris", a cargo del artista Luis Antonio Torres Villar, en el marco de la exposición 10 años de Xilografía, el evento fue gratuito y se realizó en las instalaciones de la GAV.

Mis alas de madera, muestra individual del artista plástico Fernando Pazos, en la que recorremos, siempre mirando desde lo alto, como sobrevolando, diferentes espacios en los que se evoca con nostalgia y melancolía los recuerdos del artista. La exposición estuvo del 4 al 27 de mayo.

Intrascendente, bipersonal de los artistas Luis Enrique Zela-Koort y Andrés Ennen. Proyecto que busca que el espectador cuestione el arte mismo, quiénes lo gestan, lo avalan, lo institucionalizan, a través de su condición de objeto; y cómo es percibido, a través de formatos interactivos, como brazos robóticos que dibujan, dispositivos que contemplan la posible automatización del arte, cucarachas cyborg guiadas por medio de tablets, etc. La exposición estuvo del 1 de junio al 1 de julio.

El 22 de junio se realizó el conversatorio "Arte intrascendente", organizado por el Instituto de Investigaciones Museológicas y Artísticas de la Universidad Ricardo Palma, en el marco de la muestra Intrascendente, en la que participaron Alfonso Castrillón y Augusto del Valle, junto a los artistas Andrés Ennen y Luis Enrique ZelaKoort. El evento se realizó en las instalaciones del Centro Cultural Ccori Wasi.
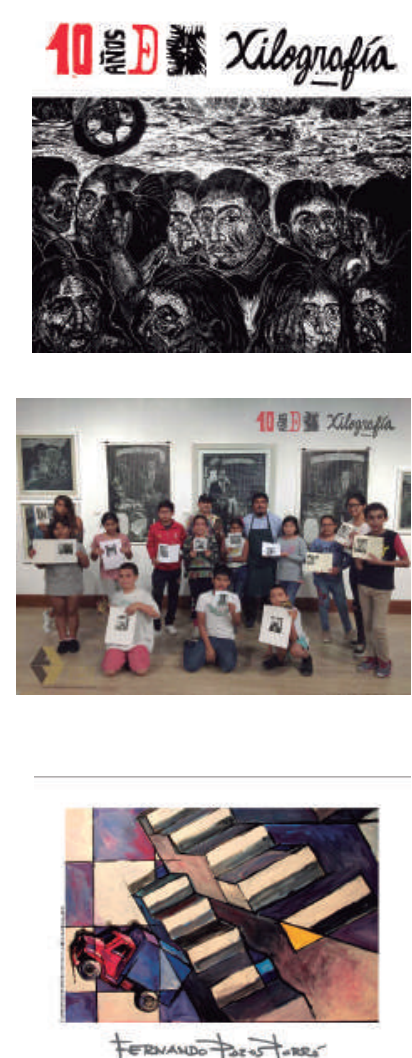

ferewardo pox जै toner MiS ALAS DE MADERA nWoine
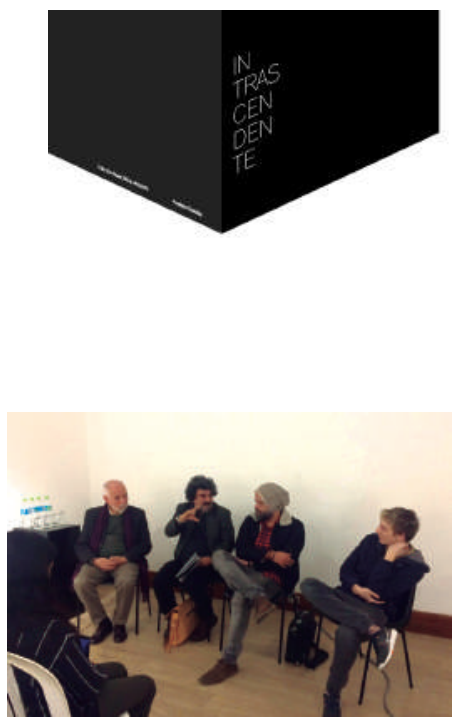

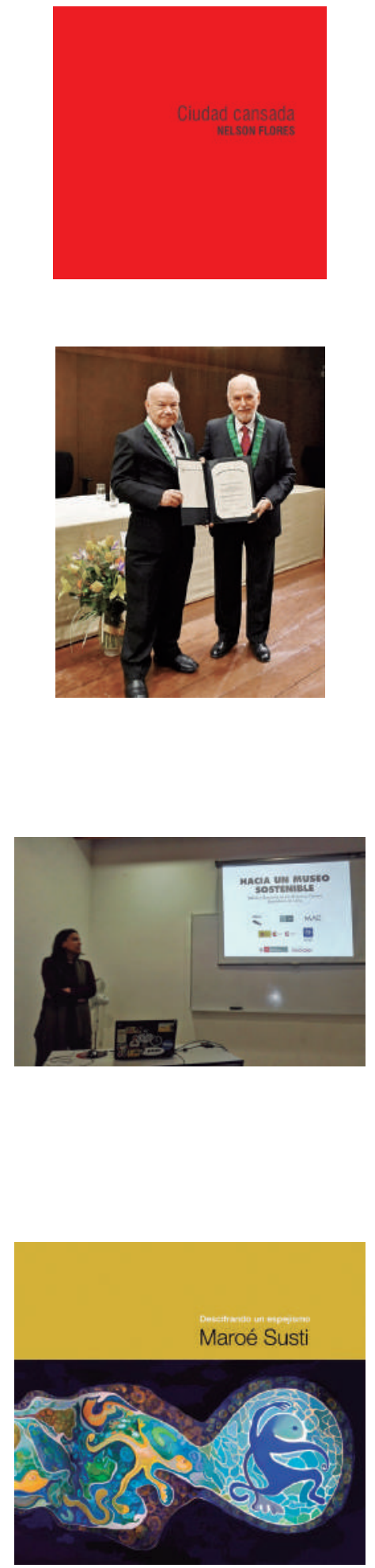

Ciudad cansada, del artista plástico Nelson Flores. La muestra de estilo hiperrealista, en la que las obras, cuyos bocetos y apuntes son llevados a cabo en el lugar de los hechos, nos transmite en tonos grises y azulados un sentimiento de soledad existencial y una evidente crítica a la sociedad contemporánea. La exposición se realizó del 6 al 29 de julio.

El viernes 13 de julio se le otorgó la distinción académica como Doctor Honoris Causa al doctor Alfonso Castrillón Vizcarra, en cuya ceremonia disertó sobre la conferencia "Evolución del pensamiento museológico". El acto tuvo lugar en el Auditorio del Centro Cultural Ccori Wasi y estuvo a cargo de la Oficina Central de Extensión Cultural y Proyección Social.

El Instituto de Investigaciones Museológicas y Artísticas, en coordinación con la Asociación Nacional de Museólogos y la Maestría en Museología y Gestión Cultural, organizaron la charla "Hacia un Museo Sostenible" sobre los resultados de la publicación Hacia un museo sostenible: Oferta y demanda de los museos y centros expositivos de Lima, a Cargo de la Lic. Gloria Lescano, realizadas en las instalaciones del Centro Cultural Ccori Wasi

Descifrando un espejismo, muestra individual de la artista Maroé Susti, en la que propone reafirmar un estado de conciencia alterno que nos otorgue la posibilidad de sumergirnos en lo más profundo, más allá de nuestros sentidos; percibir el entorno y la materia que nos rodea como una realidad en distintas escalas y dimensiones. La exposición tuvo lugar en la Galería de Artes Visuales del 2 al 26 de agosto. 
Del 10 al 13 de septiembre se realizó el $27 .^{\circ}$ Congreso Bienal del International Institute for Conservation of Historic and Artistic Works, en el que por primera vez se realizó un concurso de trabajos presentados en el Poster Session con motivo del congreso. Rosanna Kuon, docente de la maestría en Museología y Gestión Cultural, obtuvo el segundo lugar en el concurso entre cuarenta trabajos presentados, obteniendo una Mención Honrosa con el póster National Museum in Peru, Guidelines and Policies for the Relocation of Cultural Assets, por el contenido, diseño y claridad en la presentación del mismo. Trabajo conjunto desarrollado con Lorice Sivira, Maria Inés Velarde y Marcela Rosselló. En la fotografía: Rosanna Kuon y el conservador Gäel de Guichen.

El 12 de septiembre, la antropóloga María Angélica Rozas Rozas Álvarez, editora de nuestra revista, participó en el conversatorio "Publicaciones peruanas de investigación en arte hoy", donde hablamos de la historia, producción y aportes de nuestra revista Illapa Mana Tukukuq. Evento organizado por la Galería Municipal de Arte Pancho Fierro de la Municipalidad Metropolitana de Lima.

Del 11 al 13 de septiembre se llevó a cabo el VII Simposio Latinoamericano de Tensoestructuras, en el que se abarcaron temas relacionados con las tensoestructuras y su rol educativo actual, las nuevas aplicaciones tecnológicas, materiales y modelos, soporte de software, construcción y montajes, etc. El evento tuvo como sede al Centro Cultural Ccori Wasi de la Universidad Ricardo Palma.

El artista italiano Diego Esposito ha instalado una escultura suya en la región de Satka (Urales, Rusia), de acuerdo a su proyecto titulado LatitudLongitud. El bloque de piedra, en estado natural, consta de un círculo convexo de metal bruñido en el que se refleja el cielo de Siberia. Cuando Espósito estuvo en Lima instaló una escultura parecida en el ingreso de nuestro Centro Cultural Ccori Wasi, titulada Latitud $12^{\circ} 7{ }^{\prime} 3,47$ S- Longitud $77^{\circ} 1^{\prime} 46,32 \mathrm{~W}$, que forma parte del proyecto que según el artista significa la unión entre los pueblos más lejanos de la tierra. Fotos de Vasily Maximov, 2018)
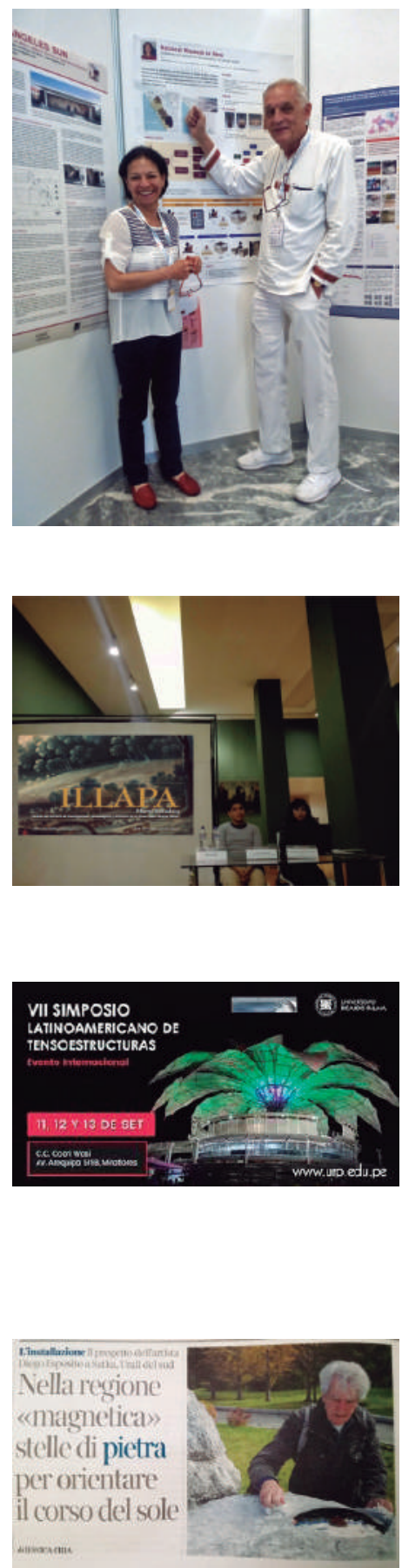

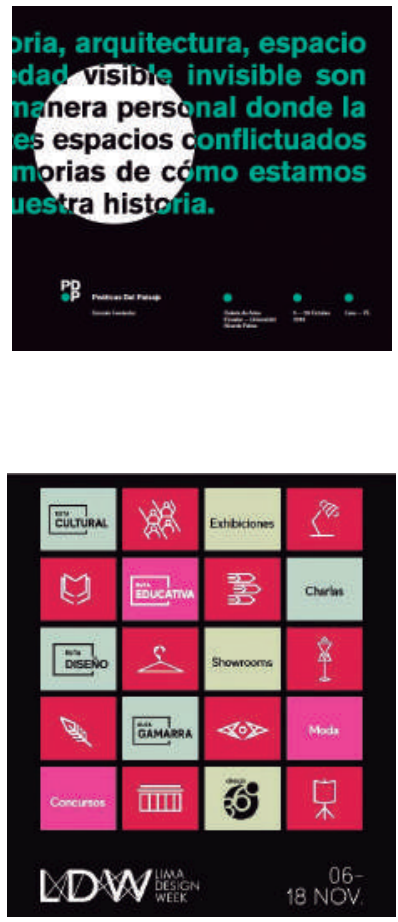

El 5 de octubre se inauguró en la Galería de Artes Visuales, Poéticas del Paisaje, unipersonal del artista Gonzalo Fernández, muestra que reúne una serie de pinturas donde convergen los continuos cambios del paisaje y una suerte de arquitectura simbólica representada por el cuerpo. La muestra fue presentada en la Galería de Artes Visuales del 5 al 29 de octubre.

Lima Design Week 2018, plataforma dedicada al diseño, presenta su sexta edición, en la que se realizaron muchas actividades en distintas partes de Lima, con el propósito de unir las manifestaciones del diseño con el arte y la cultura y, así, destacar la importancia del diseño como un gran vínculo para el desarrollo social. LDW 2018 estuvo patrocinado por la Universidad Ricardo Palma y se llevó a cabo del 7 al 19 de noviembre en la Galería de Artes Visuales y las instalaciones del Centro Cultural Ccori Wasi. 